commendable because of the current interest in the virus of Lassa fever, and the final chapter by Robinson has, rightly, a considerable amount of the new material about the hepatitis A virus, as well as an account of the classical knowledge of the present day about hepatitis B. This book deserves a place on the shelves of virus department and institute libraries-and indeed, all places where they work with viruses.

A. P. WATERSON

\title{
Clinical bacteriology
}

By P. W. Ross. 1979. Churchill Livingstone, Edinburgh. Pp. iii and 158. $£ 2.95$.

This book aims, in the words of the preface, "to provide the essentials of clinical bacteriology for those involved in the diagnosis and management of the infected patient, including medical and dental students, hospital medical staff and general practitioners". The author, who is Senior Lecturer in the Department of Bacteriology at the University of Edinburgh Medical School, has based his book on the approach used in teaching bacteriology to students in that school, namely "systems-orientated" rather than "organism-orientated". The earlier chapters are on sources and spread of infections, bacterial pathogenicity, prevention, diagnosis and treatment. These are followed by individual chapters on infections of the various systems of the body. Each chapter is followed by a few suggestions for further reading, and there is a short but adequate index.

The book provides the student with a lucid introduction to the study of bacteriology, and there is no doubt that the systems-based approach is helpful and provides information in a logical way, and the knowledge can easily be related to the student's work in anatomy, physiology and pathology. The introductory chapters are concise and clear, and the author is particularly to be commended on the section on collection of specimens and liaison with the laboratory; one hopes that the embryo doctor will appreciate from the outset the benefits to all concerned, particularly the patient, of close liaison between the clinician and the microbiologist.

Inevitably, there are some criticisms; many of these are omissions in the interests of conciseness, e.g., the author has wisely restricted the discussion of hypochlorite disinfectants to generalities and avoided the confusing matters of percentages and "parts per million" that are so essential in the use of these compounds. One would question whether the infectivity of an organism is the same as its pathogenic potential and, strictly speaking, the Bowie-Dick test is a test of steam penetration rather than successful sterilisation. In the discussion of gas gangrene, there is insufficient emphasis on hyperbaric oxygen and too much on the use of polyvalent antitoxin. The section on antimicrobial chemotherapy provides a rather cursory account of this rapidly expanding field, and there are no references in this section later than 1975 . Again, there is a clear need for conciseness in a book of this nature, but the student should be provided with more guidance in this field; e.g., the new generation of cephalosporins do not appear, and there is no mention of the severe side effects of the lincomycins.

The fairly detailed chapter on infections of the mouth reflects the author's interest, and will make the book valuable for dental as well as for medical students.

In summary, this small book will, for a modest price, provide the student of medicine or dentistry with a concise and useful introduction to the study of clinical bacteriology, minor criticisms notwithstanding.

H. W. K. Fell

\section{Medical mycology-proceedings of mycological symposia of the XII International Congress of Microbiology}

Edited by Hans-Jürgen Preusser. 1980. Gustav Fischer Verlag, Stuttgart. Pp. xv and 394. DM 178.

The 46 papers presented at this meeting are classified under Dimorphism, Ecology of human pathogenic fungi, Contamination and elimination of fungi in areas of risk, Antigenic properties 